\title{
BMJ Open Facilitators for using data from a quality registry in local quality improvement work: a cross-sectional survey of the Danish Cardiac Rehabilitation Database
}

\author{
Cecilie Lindström Egholm, ${ }^{\oplus 1,2}$ Charlotte Helmark, ${ }^{3}$ Jan Christensen, ${ }^{4}$ \\ Ann Catrine Eldh, ${ }^{5}$ Ulrika Winblad, ${ }^{6}$ Gitte Bunkenborg, ${ }^{7}$ Ann-Dorthe Zwisler, ${ }^{1}$ \\ Per Nilsen ${ }^{5}$
}

To cite: Lindström Egholm C, Helmark C, Christensen J, et al. Facilitators for using data from a quality registry in local quality improvement work: a cross-sectional survey of the Danish Cardiac Rehabilitation Database. BMJ Open 2019;9:e028291. doi:10.1136/ bmjopen-2018-028291

- Pre-publication history and additional material is published online only. To view, please visit the journal online (http://dx.doi. org/10.1136/bmjopen-2018028291).

Received 3 December 2018 Revised 16 April 2019 Accepted 23 April 2019
D) Check for updates

(c) Author(s) (or their employer(s)) 2019. Re-use permitted under CC BY-NC. No commercial re-use. See rights and permissions. Published by BMJ.

For numbered affiliations see end of article.

\section{Correspondence to}

Dr. Cecilie Lindström Egholm; cecilie.lindstrom.egholm@ rsyd.dk

\section{ABSTRACT}

Objectives To investigate use of data from a clinical quality registry for cardiac rehabilitation in Denmark, considering the extent to which data are used for local quality improvement and what facilitates the use of these data, with a particular focus on whether there are differences between frontline staff and managers.

Design Cross-sectional nationwide survey study. Setting, methods and participants A previously validated, Swedish questionnaire regarding use of data from clinical quality registries was translated and emailed to frontline staff, mid-level managers and heads of departments $(n=175)$ in all 30 hospital departments participating in the Danish Cardiac Rehabilitation Database. Data were analysed descriptively and through multiple linear regression. Results Survey response rate was 58\% (101/175). Reports of registry use at department level (measured through an index comprising seven items; score min 0 , $\max 7$, where a low score indicates less use of data) varied significantly between groups of respondents: frontline staff mean score $1.3(\mathrm{SD}=2.0)$, mid-level management mean $2.4(\mathrm{SD}=2.3)$ and heads of departments mean $3.0(\mathrm{SD}=2.5), \mathrm{p}=0.006$. Overall, department level use of data was positively associated with higher perceived data quality and usefulness (regression coefficient $=0.22, p=0.019$ ), management request for data (regression coefficient $=0.40, p=0.008$ ) and personal motivation of the respondent (regression coefficient $=1.63, p<0.001$ ). Among managers, use of registry data was associated with data quality and usefulness (regression coefficient $=0.43, p=0.027$ ), and among frontline staff, reported data use was associated with management involvement in quality improvement work (regression coefficient $=0.90, p=0.017$ ) and personal motivation (regression coefficient $=1.66$, $p<0.001$ ).

Conclusions The findings suggest relatively sparse use of data in local quality improvement work. A complex interplay of factors seem to be associated with data use with varying aspects being of importance for frontline staff and managers.
Strengths and limitations of this study

- This cross-sectional survey study presents novel data regarding use of data from a cardiac rehabilitation registry as well as on differing perceptions between staff and managers regarding application of clinical quality registry data in local quality improvement.

- The survey was nationwide, including $93 \%$ of relevant departments, with acceptable response rate $(58 \%)$ and participation of both frontline staff, mid-level managers and department heads.

- By identifying factors facilitating implementation, we hope to support management, quality improvement staff, database developers and administrators to take steps to further encourage and support use of registry data to improve quality of care.

- Although the study is based on one cardiac rehabilitation registry in Denmark, the structure and use of the registry is similar to that of other clinical quality registries, which means that the results may be transferable to other registries and to settings beyond Denmark.

\section{INTRODUCTION}

The use of clinical quality registries (CQRs) is frequently emphasised as a means for continuous quality improvement. ${ }^{12}$ By collating standardised information on clinical care processes and patient outcomes within demarcated areas of healthcare and making feedback data available to the participating sites, the use of CQRs can provide the basis for improving suboptimal practice. ${ }^{3}$

However, to achieve the purpose of quality improvement, the use of CQRs must be thoroughly implemented, including active use of the collected data for follow-up and learning opportunities. Studies indicate that this may often not be the case. A recent systematic review found that only a few high-quality studies have been able to show an effect in 
terms of improved quality of care. ${ }^{4}$ Despite substantial investments into increased use of CQR data in Sweden, national evaluations have shown that the registries have not been drivers of local quality improvement, with data use often being limited. ${ }^{5}$ On the other hand, the application of data in local quality improvement work may differ between registries, ${ }^{56}$ indicating data use may be registry and context-dependent.

Some of the determinants for use of data include: data relevance, ${ }^{78}$ perceived quality of data, timeliness of feedback,${ }^{9}$ know-how among staff, ${ }^{10}$ sufficient resources, ${ }^{5} 10$ collaboration between relevant organisational tiers ${ }^{6711}$ and engagement of both frontline staff and managers. ${ }^{12}$ Thus, while collaboration and engagement across the organisation is important, it is unknown whether staff and managers are influenced by the same determinants, and whether they share perceptions on the use of CQR data. Studies of other types of quality improvement initiatives have suggested that determinants for use of data may differ between these two occupational groups, and that managers may have more overall positive views of the initiatives compared with frontline staff. ${ }^{13-15}$ As such disparities have possible implications for the use of data, ${ }^{12}{ }^{13}$ studies in the field of CQRs seem warranted.

CQRs are typically introduced in clinical areas where there is a gap between evidence and practice. ${ }^{3}$ One such area is cardiac rehabilitation, which despite being an important part of secondary prevention for patients recovering from heart disease, ${ }^{16}$ is consistently reported to have evidence-practice gaps. ${ }^{17} 18$ CQRs with the purpose of monitoring and improving cardiac rehabilitation services have been established in at least seven countries. ${ }^{19}$ Although sizeable resources are invested into development, administration and data collection of these CQRs, ${ }^{319}$ it remains unclear to what extent the data are being used and what drives the use of data for local quality improvement among registries in this clinical area. The need for knowledge on these aspects is underscored by the fact that data-driven quality improvement currently is high on the healthcare agenda, with CQRs potentially having significant roles in delivering data. ${ }^{2021}$

The objective of this study was to investigate the use of data from a CQR for cardiac rehabilitation in Denmark, considering the extent to which data are used for local quality improvement and what facilitates the use of these data, with a particular focus on whether there are differences between frontline staff and managers. The CQR in question represents a nationwide registry based on international evidence, intended to be used primarily for quality improvement. ${ }^{22}$

\section{METHODS}

\section{Study design}

This cross-sectional study used a nationwide survey questionnaire provided to frontline staff and managers who work with cardiac rehabilitation and report data to The Danish Cardiac Rehabilitation Database.
The Danish Cardiac Rehabilitation Database

The Danish Cardiac Rehabilitation Database has been operating since 2015 and is based on clinical guideline recommendations. ${ }^{22}$ Participation is mandatory for all departments delivering phase II (postdischarge) cardiac rehabilitation. ${ }^{22}{ }^{23}$ Implementation and use of the database is a local responsibility, with possibility to obtain support from a database quality manager at The Danish Clinical Registries, from quality registry coordinators in the healthcare region, or from local quality improvement units. Data collection is a combination of manually entered data (a task performed by clinicians and/or medical secretaries) and automated data-capture from patient administrative systems. ${ }^{22}$ Results on 13 selected process and outcome indicators are available through regional web-based information systems (updated monthly) and through annual reports, which are displayed publicly. Data are reported on a local, regional and national level and presented according to standards, for the opportunity of benchmarking and intra-site and inter-site learning.

\section{Nationwide survey}

For the purpose of this study, we applied a generic survey questionnaire, the Quality improvement While Adopting Quality register outcomes survey (QWAQ). QWAQ intends to measure a range of aspects that may facilitate use of CQR data for quality improvement work, and consists of 50 items regarding quality of clinical care, quality of registry data, organisational conditions for registry work and use of data for quality improvement. ${ }^{12}$ All items are scored on 4-point or 5-point Likert scales, and form six indexes covering: 'the healthcare unit's use of registry data' (seven items); 'data quality and usefulness' (five items); 'support from outer setting' (three items); 'resources' (four items); 'management request for registry data' (four items) and 'management involvement in registry-based quality improvement' (two items). The remaining 20 items are background (sex, age, profession, role and experience with registry) and independent items. The formation of the indexes was based on theoretical assumptions from the field of quality improvement and implementation, empirical knowledge from the original developers' work as well as factor analysis. ${ }^{12}$

QWAQ, which was developed in Sweden, was translated and cross-culturally adapted into Danish using widely recognised methodology. ${ }^{24}$ The prefinal Danish version was pilot-tested for acceptability, clarity and cultural applicability through cognitive interviews among registry users $(n=15)$ representing different groups of staff (eg, frontline staff, managers) with different roles and experiences with registries. Furthermore, once study data were collected, Cronbach's $\alpha$ was used to evaluate the internal consistency reliability of the indexes. The translation and validation is described in detail in online supplementary file 1. 


\section{Respondents and procedure}

All Danish hospital departments providing cardiac rehabilitation and who report data to the Danish Cardiac Rehabilitation Database $(n=30)$ were included in the study. Potential respondents included frontline staff from the multidisciplinary cardiac rehabilitation teams, mid-level managers and heads of departments.

Respondents were strategically chosen based on roles and positions. The roles of the individual staff members can vary according to local arrangements, but in general, frontline staff collect and feed data into the registry, while managers on both mid-level and head of department level are politically expected to take on a leading role in use of data for quality improvement. ${ }^{25}$ Furthermore, we aimed to identify the frontline staff members who were most informed about the registry.

The respondents were identified through official websites, or when not available, by contacting each department directly, retrieving name, sex, work email address and position. Invited frontline staff from each department included: a cardiac rehabilitation nurse coordinator, a physiotherapist and a dietitian. A nurse manager and a chief physician were invited to represent the mid-level management, and finally, the heads of the departments included the leading physician, leading nurse and leading physiotherapist/occupational therapist. Some departments did not have all the frontline staff members and managerial positions; consequently, between four and eight individuals from each department were invited.

The survey questionnaire was distributed electronically by email in May 2018 (software: SurveyXact, Rambøll Management, Århus, Denmark (www.surveyxact.dk). In case of non-respondence two reminders were sent, after 7 and 14 days, respectively. A separate, single-question survey was emailed to remaining non-responders asking about the reasons for not responding to the survey.

\section{Statistical analyses}

Descriptive statistics were used to characterise respondents and non-respondents (sex, profession, role in relation to the registry and number of years in this role) and to show the distribution of responses to each item. The items were dichotomised, where 'agree' and 'strongly agree' were merged and coded 'agree' and the remaining two or three response categories were coded 'do not agree'.

Index scores were calculated as sums of raw scores ('do not agree' was coded 1, 'strongly agree' was coded 5) and dichotomised scores ('do not agree' was coded 0, 'agree' was coded 1). Thus, a higher score indicated more use of data or more resources. The index scores were stratified and presented according to the different groups of staff (frontline staff, mid-level management, head of department). After checking data for normal distribution with histograms and quantile-quantile plots, the non-parametric tests Kruskal-Wallis and Wilcoxon signed-rank tests

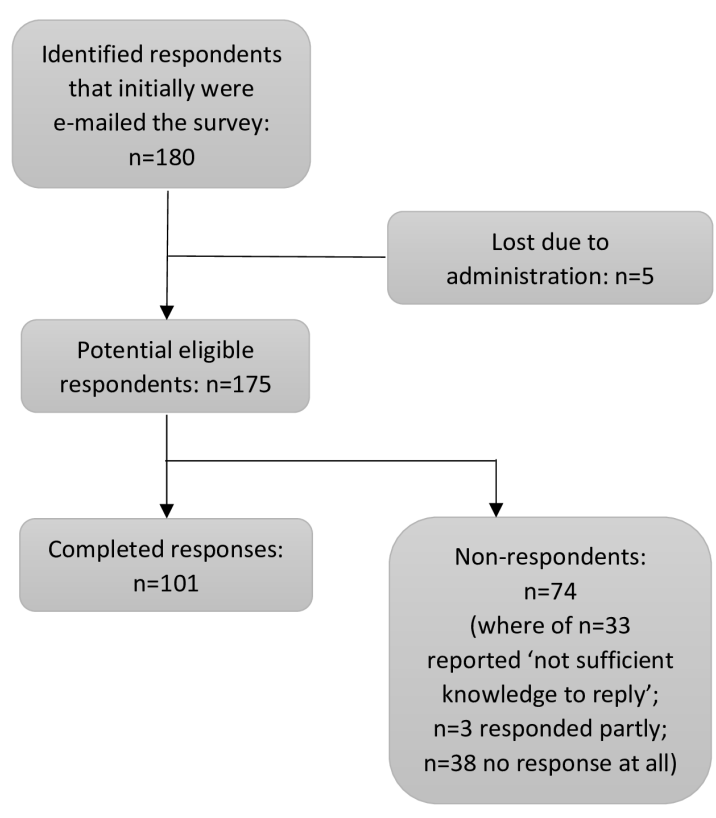

Figure 1 Study flow diagram.

were used to investigate if differences existed between groups.

Multiple linear regression analysis was used to investigate the factors facilitating use of data for quality improvement work for the different groups of staff respectively and combined. The index 'the healthcare unit's use of registry data' was used as the dependent variable and the five other index scores in the QWAQ as independent variables. Furthermore, a single variable "I am motivated to improve the cardiac rehabilitation care we provide as a result of our results in the registry" was included to further assess individual motivation. ${ }^{926}$

All analyses were performed using STATA statistical software V.15.0 (StataCorp, College Station, Texas, USA). A significance level of 0.05 was applied.

\section{RESULTS \\ Participants}

Out of the 30 departments, 28 were represented in this study. A study flow diagram is presented in figure 1 . The survey was sent to 175 individuals of whom 101 responded $(58 \%)$, of which 62 were frontline staff, 19 mid-level managers and 20 heads of departments (table 1). Response proportions differed among the different groups of staff, with $78 \%$ of frontline staff responding and $35 \%$ of heads of departments. Characteristics of respondents and non-respondents are presented in table 1.

Most respondents were female $(87 \%)$, aged 41 years or older $(84 \%)$, with three or more years of experience with their role in the registry $(68 \%)$. Among non-respondents, 33 (mainly managers) reported not having sufficient knowledge concerning the registry to respond to the survey questionnaire. No other reasons for non-response were reported, although two managers stated that 
Table 1 Characteristics of respondents and non-respondents

\begin{tabular}{|c|c|c|}
\hline & Respondents $n=101$ & Non-respondents $n=74$ \\
\hline & n (column \%) & $n$ \\
\hline \multicolumn{3}{|l|}{ Sex } \\
\hline Male & $13(13 \%)$ & 23 \\
\hline \multicolumn{3}{|l|}{ Group of staff } \\
\hline $\begin{array}{l}\text { Mid-level management (nurse managers and chief } \\
\text { physicians) }\end{array}$ & $19(19 \%)$ & 19 \\
\hline $\begin{array}{l}\text { Head of department (leading physician, leading nurse, } \\
\text { leading physio-occupational therapist) }\end{array}$ & $20(20 \%)$ & 37 \\
\hline \multicolumn{3}{|l|}{ Role within the registry ${ }^{\star} \dagger$} \\
\hline Manager & $24(24 \%)$ & $\ddagger$ \\
\hline Other & $17(17 \%)$ & $\ddagger$ \\
\hline \multicolumn{3}{|l|}{ No. of years in this role ${ }^{*} \dagger$} \\
\hline$<1$ & $11(11 \%)$ & $\ddagger$ \\
\hline $1-2$ & $20(21 \%)$ & $\ddagger$ \\
\hline$>3$ & $66(68 \%)$ & $\ddagger$ \\
\hline
\end{tabular}

*Self-reported.

†Multiple responses possible.

‡Data not available for non-respondents.

they, besides insufficient knowledge, did not have enough time.

\section{The extent of data use in local quality improvement work}

The distribution of responses to each item, dichotomised with a cut-off at 'agree', is shown in table 2. There were significant variations in the responses of frontline staff, mid-level managers and heads of departments concerning resources for analysing data and performing improvement work, perceived support from own department, the degree to which they take part in analysis of data and report to others and perceptions of department's use of data to identify areas for change.

The mean sum score on the dichotomised index responses are presented in table 3. For 'unit's use of data' (min $0, \max 7$, where a lower score indicated less use of data), frontline staff scored a mean of $1.3(\mathrm{SD}=2.0)$, mid-level management a mean of $2.4(\mathrm{SD}=2.3)$ and heads of departments a mean of $3.0(\mathrm{SD}=2.5)$. Testing for analysis of variance between the three groups of staff (ie, frontline staff, mid-level management and heads of departments) revealed that there were significant differences between the groups for three indexes: 'unit's use of data' $(p=0.006)$, 'resources' $(p=0.04)$ and 'management request for registry data' $(p=0.006)$ (table 3$)$. The disagreements were in all circumstances found between frontline staff and the two groups of managers. As there were no disagreements between mid-level management and heads of departments, we decided to merge these two respondent groups to a new group: management, for use in the multiple linear regression analysis.

The means of non-dichotomised index scores are depicted in online supplementary file 2.

\section{Facilitators for use of data}

The multiple linear regression analysis for all respondents showed a statistically significant association between the dependent variable 'unit's use of data', the indexes 'data quality and usefulness' (regression coefficient $=0.22$, $\mathrm{p}=0.019$ ), 'management request for data' (regression coefficient $=0.40, \mathrm{p}=0.008$ ) and the single variable "I am motivated" (regression coefficient=1.63, p<0.001) (table 4). The six independent variables together explained $56 \%$ of the total variance in 'unit's use of data' $\left(r^{2}=0.56\right)$.

Analysing the frontline staff and manager group respectively, different aspects were important for use of registry data in the two groups. Among managers, 'unit's use of data' was significantly associated with 'data quality and usefulness' (regression coefficient $=0.43, \mathrm{p}=0.027$ ), and among frontline staff, reported data use was associated with 'management involvement in quality improvement work' (regression coefficient $=0.90, \mathrm{p}=0.017$ ) and "I am motivated" (regression coefficient=1.66, $\mathrm{p}<0.001$ ) (table 4). 
Table 2 Distribution of responses to index items and single items in the QWAQ* questionnaire by staff groups in hospital departments working with the Danish Cardiac Rehabilitation Database

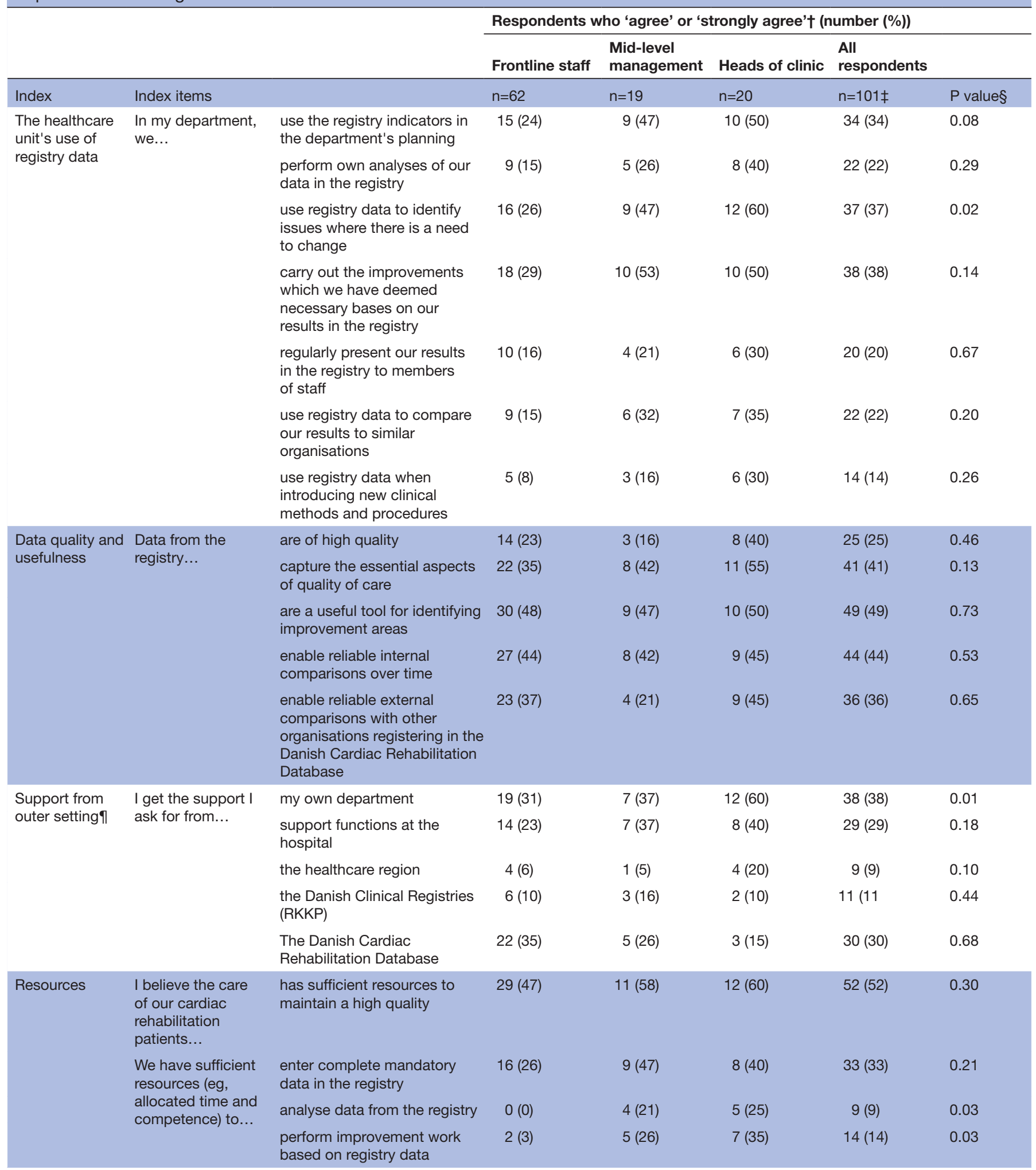

Continued 
Respondents who 'agree' or 'strongly agree'† (number (\%))

Mid-level All

Frontline staff management Heads of clinic respondents

\begin{tabular}{|c|c|c|c|c|c|c|c|}
\hline \multirow[t]{3}{*}{$\begin{array}{l}\text { Management } \\
\text { request for } \\
\text { registry data }\end{array}$} & $\begin{array}{l}\text { My manager (the } \\
\text { manager I report } \\
\text { to)... }\end{array}$ & calls for data from the registry & $8(13)$ & $3(16)$ & $5(25)$ & $16(16)$ & 0.48 \\
\hline & \multirow{2}{*}{$\begin{array}{l}\text { Our results in the } \\
\text { Danish Cardiac } \\
\text { Rehabilitation } \\
\text { Database are called } \\
\text { for by... }\end{array}$} & department managers & $11(18)$ & $7(37)$ & $10(50)$ & $28(28)$ & 0.11 \\
\hline & & the healthcare region & $4(6)$ & $6(32)$ & $5(25)$ & $15(15)$ & 0.09 \\
\hline $\begin{array}{l}\text { based quality } \\
\text { improvement }\end{array}$ & $\begin{array}{l}\text { My manager (the } \\
\text { manager I report } \\
\text { to)... }\end{array}$ & $\begin{array}{l}\text { initiates improvement work } \\
\text { based on registry data }\end{array}$ & $8(13)$ & $4(21)$ & $4(20)$ & $16(16)$ & 0.57 \\
\hline
\end{tabular}

Single items

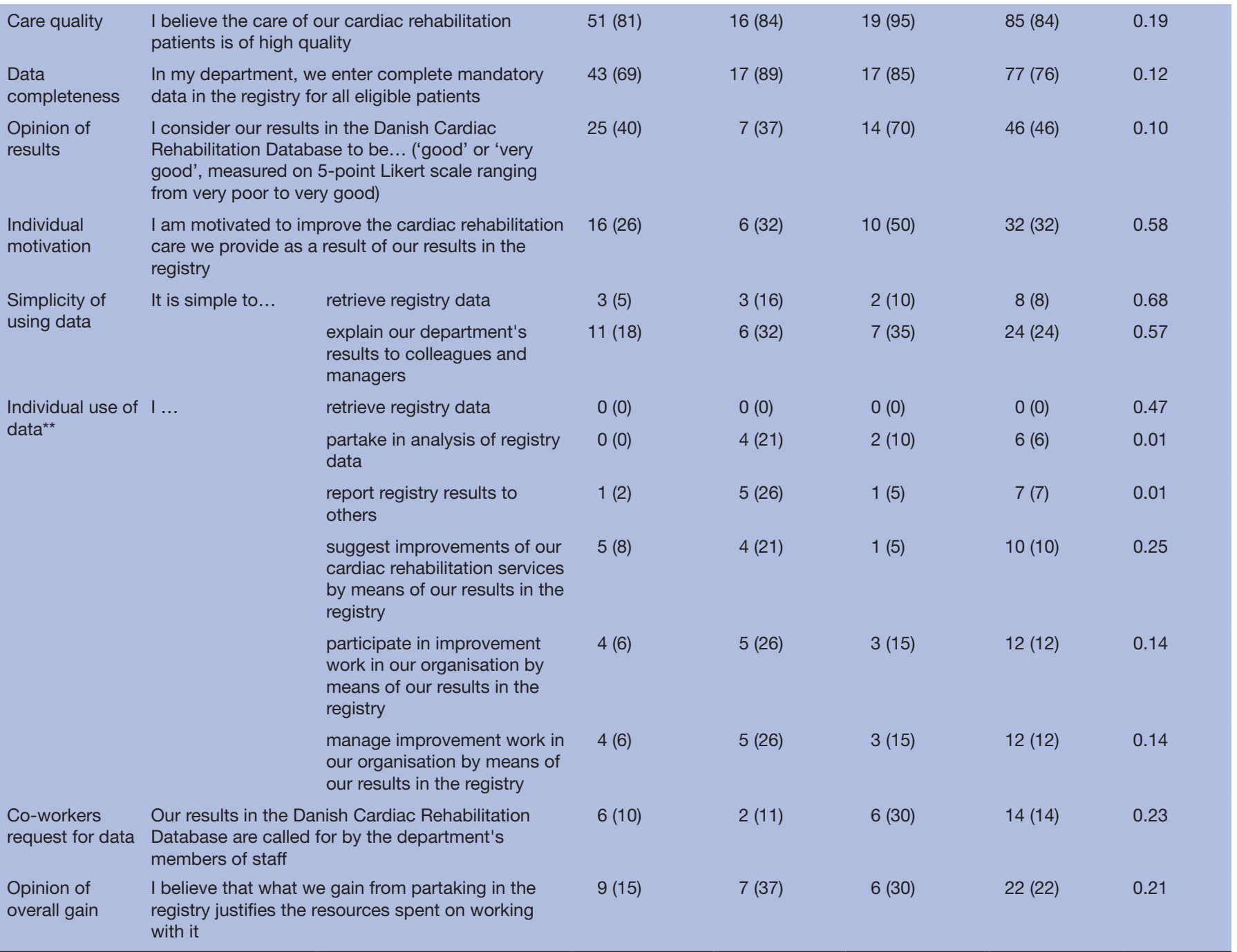

*QWAQ=Quality improvement While Adopting Quality register outcomes survey.

†Response options were on a 5-point Likert scale (strongly disagree, disagree, neither agree nor disagree, agree, strongly agree), where not otherwise indicated.

$\ddagger$ Missing: median 9 (range 6-18).

$\S P$ value calculated using Kruskal-Wallis test.

१The displayed index is our revised version of the index with five items: The original index contained three items: 'support functions at the hospital', 'the Danish Clinical Registries'/('the central registry organisation' in the generic version), 'the (registry name)'. More detail in online supplementary file 1.

${ }^{\star *}$ Likert scale with four response options: never, seldom, sometimes, often. 
Table 3 Differences in index scores between frontline staff, mid-level management and heads of departments

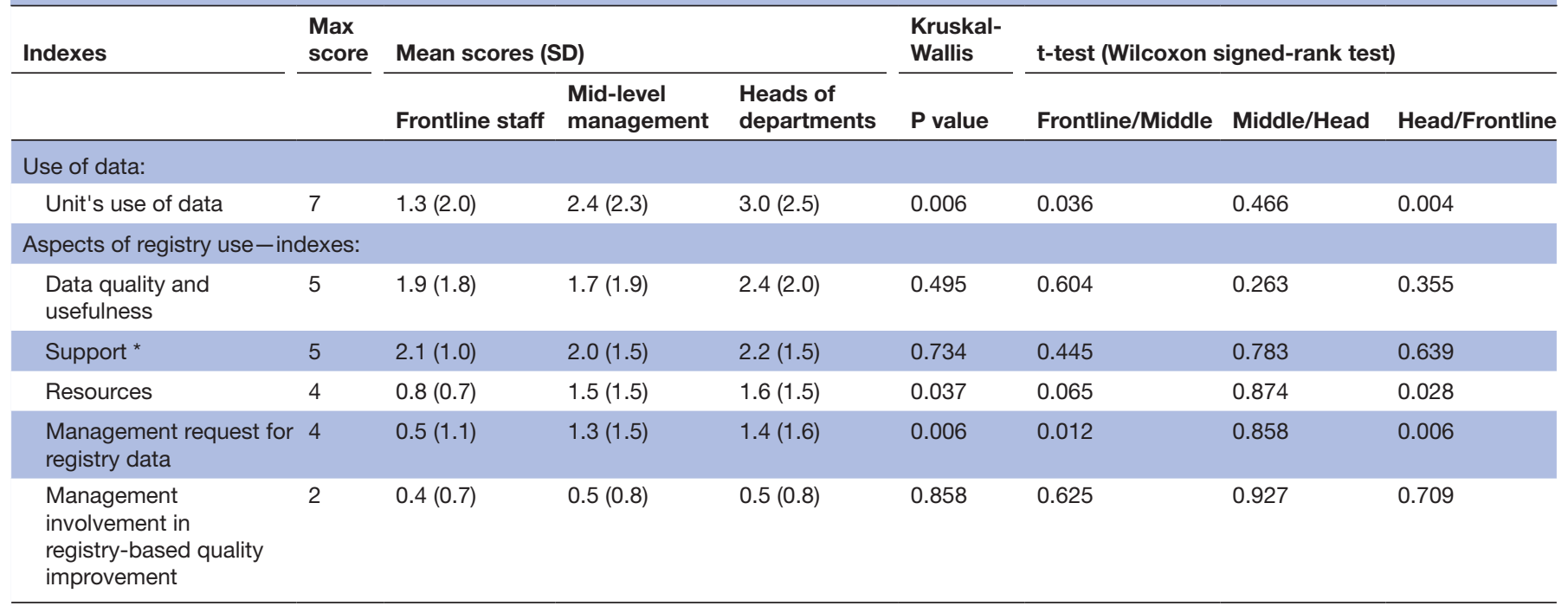

${ }^{\star}$ The support index was dichotomised in the regression analyses; no support vs support from at least one source (more detail in online supplementary file 1).

\section{DISCUSSION}

This study sought to survey the use of data from the Danish Cardiac Rehabilitation Database to determine the extent to which data are used for local quality improvement and what facilitates the use of these data. Findings indicate that data from the registry were used in local quality improvement work to a relatively limited extent. Frontline staff on average reported using data for one of seven suggested purposes, while heads of departments reported using it for three. It was not possible to distinguish between high and low extent of data use per se, as there is no shared understanding of standards for use of CQR data yet. It may be that such standards are unrealistic to establish and that use of data should always be judged based on the individual case. In the current study, we regard the use of data to be relatively low as only $29 \%$ of frontline staff and $50 \%$ of heads of department in the present study reported to carry out data-driven improvements based on results in the registry, and less than one in three present results to members of staff. Furthermore, in a previous study we identified gaps between evidence and practice in nearly all departments providing cardiac rehabilitation in Denmark. ${ }^{18}$

While the literature regarding use of CQR data is sparse, our findings are comparable to the findings of Fredriksson et $a l^{6}{ }^{6}$ They studied the use of data in local quality improvement, according to physicians and managers in three Swedish CQRs (stroke, gallstone

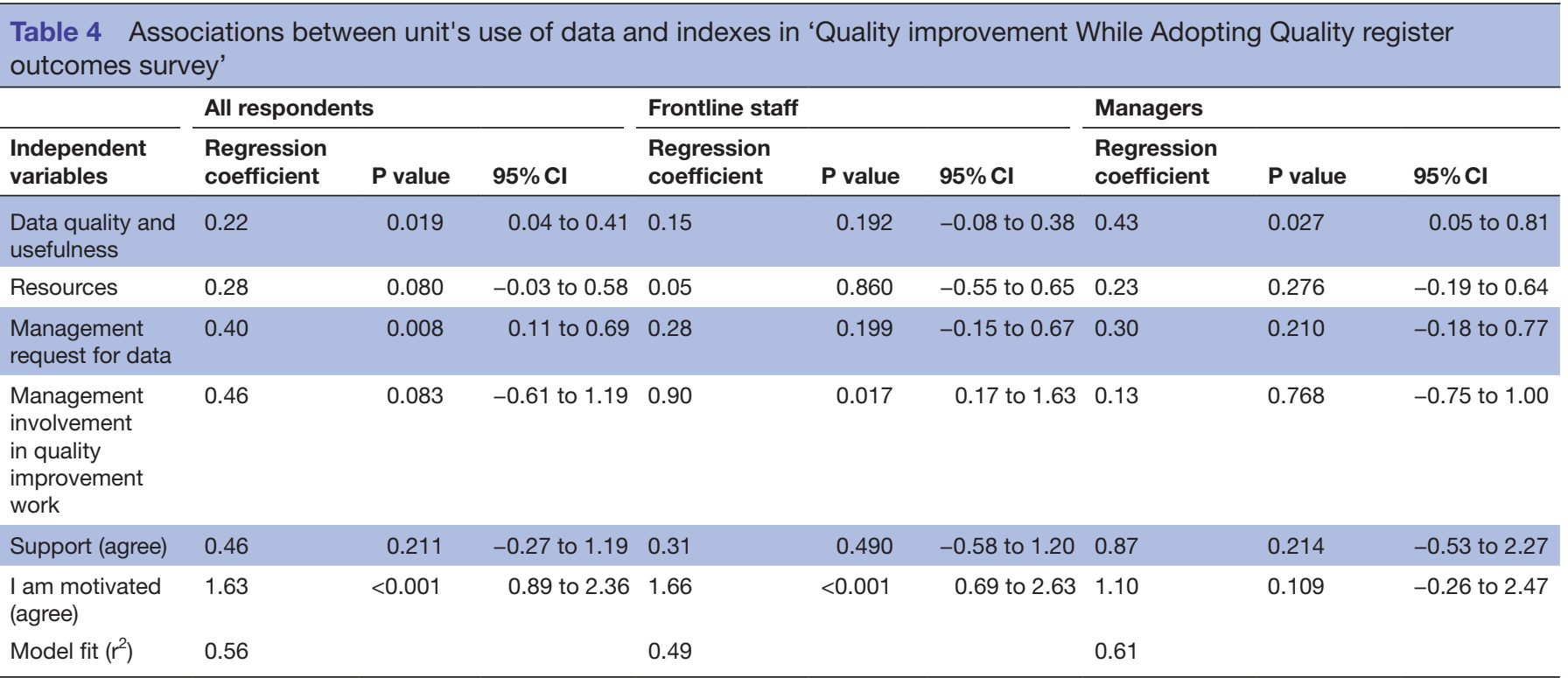

$r^{2}=$ the percentage of variation in the response that is explained by the model. 
surgery and lung cancer), using the original version of the QWAQ. They found similar levels of reported use of data in the gallstone surgery and lung cancer registries, while it was higher in the stroke registry. The latter is considered to be more developed in terms of feedback with national benchmarks and validation of data. ${ }^{6}$ Such a degree of maturity has been suggested as a possible explanation for differences in use of data between registries. ${ }^{5}{ }^{27}$

In the present study, a specific focus was on whether frontline staff and managers' perceptions of data use differed. Frontline staff reported use of data on a department level to be lower than that of their managers. We found no studies investigating the perceived extent of use of CQR data among frontline staff as a separate group, nor was it possible to establish which (if any) of the two groups were 'right', that is, whether responses correspond to objective measures of data use. In a previous study of a patient safety programme, managers were found to hold a more positive view of the effectiveness of the initiative than frontline staff. ${ }^{13}$ Similar to the proposed explanation in that study, the different perceptions between users of the Danish Cardiac Rehabilitation Registry could be explained by managers' greater overview, having insight into quality improvement initiatives across the organisation. ${ }^{13}$ However, it could also be that managers simply do not know as much about registry use in practice as their frontline employees, resulting in overly optimistic estimates. Yet another possibility is that the managers' responses may be more influenced by social desirability bias, that is, over-reporting of desirable behaviours. Data-driven quality improvement is high on the healthcare policy agenda and managers (particularly heads of departments) are likely aware that their organisation is being benchmarked against others in annual reports and in other national, publicly available data such as the National Healthcare Quality Programme. ${ }^{1}$ Frontline staff, on the other hand, may not be faced with such pressure to apply data. Instead, they often focus on entering data. ${ }^{7}$ The differing perceptions between frontline staff and managers underscore the importance of accounting for perceptions of both groups when conducting studies of quality improvement initiatives ${ }^{13} 15$ to obtain a nuanced view from stakeholders in different positions.

While reported data use was positively associated with the quality and usefulness of data, management requesting data and personal motivation, none of these aspects were rated highly by the respondents. These aspects have previously been documented as influencing effectiveness of feedback from registries ${ }^{9}$ and thus would seem crucial to address and improve in order to maximise the chances of usage of registry data. The negative perceptions of data quality underscores the challenges of creating a CQR that captures the essential aspects of care in relevant quality indicators. ${ }^{39}$ This may be particularly difficult in a field such as cardiac rehabilitation, where a large proportion of the clinical intervention centres on lifestyle changes and improving quality of life, and where socioeconomic vulnerability among patients may add specific barriers to the perceived validity of data. ${ }^{28}$

In agreement with previous Swedish findings, ${ }^{12}$ resources, such as time and competencies, and receiving support were not associated with use of registry data. This may seem surprising, as it has been highlighted as potentially important by implementation frameworks such as the Consolidated Framework for Implementation Research ${ }^{26}$ and contradicts previous reports. ${ }^{5} 1029$ Resources and support were also associated with use of data in univariate analyses (data not shown). Hence, it appears that resources and support are reduced in priority when compared with other aspects, reflecting a complex interplay of factors that influence the extent of data use. This complexity increases further when considering that different aspects seemed to be important for data use among frontline staff and managers.

The QWAQ covers a range of facilitators for use of data, ${ }^{12}$ however, all potentially relevant facilitators cannot be investigated. This is a common limitation of survey research, where questionnaire developers must weigh precision against the response burden. Still, our survey has yielded important insights into the relative importance of different facilitators. ${ }^{30}$ Further explanations concerning the use of CQR data can be derived from our previous qualitative studies in the cardiac rehabilitation field. For example, we have found that feedback data may not reach the frontline staff because it fails to pass through complex delivery pathways, staff may not know that local feedback data exists and a culture supporting quality improvement may not have been established ${ }^{31}$ (Helmark et al; article accepted for publication). Other plausible explanations, suggested by our previous work and supported by other scholars, are that roles and responsibilities for acting on data are unclear and that there is a general lack of time and understanding regarding the use of CQRs in improvement work in healthcare. ${ }^{1527}$ Furthermore, clinicians tend to have their own perceptions of what constitutes quality of cardiac rehabilitation and may dismiss the defined indicators. ${ }^{31} 32$

We regard it as an important finding that nearly half of the survey non-responders stated that they could not respond due to lack of knowledge of the registry. The majority of these reports came from managers, particularly heads of departments. Although it cannot be expected that managers have detailed knowledge of CQR use in daily practice, policy documents emphasise that they should have a strong focus on data-driven quality improvement and intervene when quality targets are not met. ${ }^{25}$ Knowledge of the registry including how to apply data in improvement work is important to be able to link efforts to mission and strategic objectives, to allocate responsibilities and secure resources and to motivate employees. ${ }^{33}$ It has been highlighted previously that managers often have inadequate knowledge and spend too little time on quality improvement to meet these important objectives. 334 


\section{Strengths and limitations}

This is the first study to investigate how and to what extent data from a cardiac rehabilitation CQR is used for quality improvement and is an important first step in understanding how these types of registries may contribute to improved quality of care. However, the fact that only one CQR for cardiac rehabilitation was included limits the generalisability of the findings. In addition, we do not know the extent to which the self-reported use of data correlates with actual use. Previous studies propose that actual use may be lower than study findings due to social desirability bias and response bias, as the most active registry users are most likely to respond. ${ }^{56}$

The Danish Cardiac Rehabilitation Database was relatively new at the time of the study, having been in full operation for only 3 years. This time period is generally regarded as sufficient for implementation of a CQR according to the Danish Clinical Registries. ${ }^{23}$ It may nonetheless have influenced the quality of the data in the registry, and furthermore, users may not yet have achieved full confidence in applying feedback data. However, full rounds of audit and feedback had been completed, and monthly updated feedback on indicators had been available for 2 years.

The sample size in the study was relatively small, but it still represents $93 \%$ of the cardiac rehabilitation units in Denmark and had an acceptable response rate of $58 \%$. The survey had a broad participation of frontline staff, mid-level nurse managers and physicians and department managers. However, the reported low level of knowledge of the registry narrowed the number of relevant respondents to the survey. The sample size limited the statistical power of the analyses, thus restraining our possibility to include variables in the regression analyses.

\section{CONCLUSION}

This survey study among frontline staff and managers employed in clinical departments participating in the Danish Cardiac Rehabilitation Database indicate a relatively limited use of data from the database, where frontline staff reported use to be lower than that of their managers. Factors associated with use of data were the perceived data quality and usefulness, management request for data and personal motivation to use data. A difference between managers and frontline staff was found, as data quality and usefulness was important for managers' reports of data use, while frontline staff reported use to be associated with their own motivation and with management involvement in quality improvement work. These findings suggest that a complex interplay of factors is associated with use of CQR data, with different aspects being important to different types of users. Furthermore, it emphasises the need to include both managers and frontline staff when evaluating use of CQRs.

Although translation of the results from this study to other registries and settings should be done with caution, our results combined with the body of literature in the implementation science field suggest that while in the planning process of a new registry, the quality of the $\mathrm{CQR}$ and the readiness to receive it in practice should be carefully evaluated. Future studies should evaluate initiatives to enhance cardiac rehabilitation registries' data quality and relevance, and to build quality improvement capacity among clinical teams and their managers with regard to applying CQRs.

\section{Author affiliations}

${ }^{1}$ The Danish Knowledge Centre for Rehabilitation and Palliative Care, University of Southern Denmark and the Region of Southern Denmark, Odense, Denmark ${ }^{2}$ Department of Medicine, Holbaek University Hospital, Holbaek, Denmark ${ }^{3}$ Department of Cardiology, Zealand University Hospital, Roskilde, Roskilde, Denmark

${ }^{4}$ Department of Occupational and Physiotherapy, Copenhagen University Hospital, Rigshospitalet, Copenhagen, Denmark

${ }^{5}$ Department of Medical and Health Sciences, Linköping University, Linköping, Sweden

${ }^{6}$ Department of Public Health and Caring Sciences, Uppsala University, Uppsala, Sweden

${ }^{7}$ Department of Anesthesiology, Holbaek University Hospital, Holbaek, Denmark

Acknowledgements The authors would like to thank all the informants for taking their time to participate in the study. The authors would also like to thank Sarah Egelund Frausing and Tina Broby Mikkelsen for assistance with data collection.

Contributors CLE, GB, ADZ, CH and PN designed the study. CLE, CH, UW and ACE took part in translation and cultural adaption of the survey. CLE conducted the survey, and together with JC performed the analysis, with the other authors being critical peers. CLE drafted the manuscript with intellectual contribution of all coauthors. All authors read and approved the final manuscript.

Funding This work was supported by the Unit for Production, Research and Innovation, Region Zealand; the Department of Medicine, Holbaek University Hospital; The Danish Knowledge Centre for Rehabilitation and Palliative Care, University of Southern Denmark and Odense University Hospital, Southern Region of Denmark; and the Region Zealand Regional Research Fund.

Disclaimer The funding bodies had no role in the design of the study, in the collection, analysis and interpretation of data or in writing the manuscript.

Competing interests CLE was functioning as a secretary for the chair of the Danish Cardiac Rehabilitation Database steering committee during work with the study. The study was independent, conducted apart from this role. $\mathrm{CH}$ is a board member of the steering committee for the Danish Cardiac Rehabilitation Database.

Patient consent for publication Not required.

Ethics approval Prior to conducting this study, permission to translate and crossculturally adapt the QWAQ was obtained from the copyright holders (Ann Catrine Eldh and Ulrika Winblad). The study was approved by the Danish Data Protection Agency through Region Zealand, REG-149-2015 . No ethical approval was necessary according to Danish law, and return of a completed questionnaire was regarded as giving consent to participation in the study.

Provenance and peer review Not commissioned; externally peer reviewed.

Data sharing statement Data are available from the first author on reasonable request.

Open access This is an open access article distributed in accordance with the Creative Commons Attribution Non Commercial (CC BY-NC 4.0) license, which permits others to distribute, remix, adapt, build upon this work non-commercially, and license their derivative works on different terms, provided the original work is properly cited, appropriate credit is given, any changes made indicated, and the use is non-commercial. See: http://creativecommons.org/licenses/by-nc/4.0/.

\section{REFERENCES}

1. Sundheds- og ÆEldreministeriet, KL, Danske Regioner. Nationale mål for sundhedsvæsenet [National healthcare quality programme]. Denmark 2016.

2. Bhatt DL, Drozda JP, Shahian DM, et al. ACC/AHA/STS Statement on the Future of Registries and the Performance Measurement Enterprise. J Am Coll Cardiol 2015;66:2230-45. 
3. Gliklich RE, Dreyer NA, Leavy MB, eds. Registries for Evaluating Patient Outcomes: A User's Guide. Third Edition. Rockville, MD: Agency for Healthcare Research and Quality, 2014. Two volumes. (Prepared by the Outcome DEcIDE Center (Outcome Sciences, Inc., a Quintiles company) under Contract No. 290200500351 TO7.) AHRQ Publication No. 13(14)-ECH111.

4. Hoque DME, Kumari V, Hoque M, et al. Impact of clinical registries on quality of patient care and clinical outcomes: A systematic review. PLoS One 2017;12:e0183667.

5. Vårdanalys. Lapptäcke med otillräcklig täckning. Slutvärdering av satsningen på nationella kvalitetsregister. Rapport 2017:4. [Patchwork with insufficient coverage. Final evaluation of the efforts for national quality registries. Report 2017:4]. Stockholm, Sweden 2017.

6. Fredriksson M, Halford C, Eldh AC, et al. Are data from national quality registries used in quality improvement at Swedish hospital clinics? Int J Qual Health Care 2017;29:909-15.

7. Eldh AC, Fredriksson M, Vengberg S, et al. Depicting the interplay between organisational tiers in the use of a national quality registry to develop quality of care in Sweden. BMC Health Serv Res 2015;15:519.

8. Gude WT, Roos-Blom MJ, van der Veer SN, et al. Health professionals' perceptions about their clinical performance and the influence of audit and feedback on their intentions to improve practice: a theory-based study in Dutch intensive care units. Implement Sci 2018;13:33.

9. van der Veer SN, de Keizer NF, Ravelli AC, et al. Improving quality of care. A systematic review on how medical registries provide information feedback to health care providers. Int J Med Inform 2010;79:305-23.

10. Eldh AC, Fredriksson M, Halford C, et al. Facilitators and barriers to applying a national quality registry for quality improvement in stroke care. BMC Health Serv Res 2014;14:354.

11. Fredriksson $M$, Eldh $A C$, Vengberg $S$, et al. Local politicoadministrative perspectives on quality improvement based on national registry data in Sweden: a qualitative study using the Consolidated Framework for Implementation Research. Implement Sci 2014;9:189.

12. Eldh AC, Wallin L, Fredriksson M, et al. Factors facilitating a national quality registry to aid clinical quality improvement: findings of a national survey. BMJ Open 2016;6:e011562.

13. Parand A, Burnett S, Benn J, et al. The disparity of frontline clinical staff and managers' perceptions of a quality and patient safety initiative. J Eval Clin Pract 2011;17:1184-90.

14. Birken SA, Lee SY, Weiner BJ, et al. Improving the effectiveness of health care innovation implementation: middle managers as change agents. Med Care Res Rev 2013;70:29-45.

15. Price M, Fitzgerald L, Kinsman L. Quality improvement: the divergent views of managers and clinicians. J Nurs Manag 2007;15:43-50.

16. Piepoli MF, Corrà U, Adamopoulos S, et al. Secondary prevention in the clinical management of patients with cardiovascular diseases. Core components, standards and outcome measures for referral and delivery. Eur J Prev Cardiol 2014;21:664-81.

17. Bjarnason-Wehrens B, McGee H, Zwisler AD, et al. Cardiac rehabilitation in Europe: results from the European Cardiac
Rehabilitation Inventory Survey. Eur J Cardiovasc Prev Rehabil 2010;17:410-8.

18. Lindström Egholm C, Rossau HK, Nilsen P, et al. Implementation of a politically initiated national clinical guideline for cardiac rehabilitation in hospitals and municipalities in Denmark. Health Policy 2018;122:1043-51.

19. Poffley A, Thomas E, Grace SL, et al. A systematic review of cardiac rehabilitation registries. Eur J Prev Cardiol 2017;24:1596-609.

20. Davos $\mathrm{CH}$. Seeking best practices for cardiac rehabilitation registries in Europe. Eur J Prev Cardiol 2017;24:1925-6.

21. Thomas RJ, Balady G, Banka G, et al. ACC/AHA Clinical Performance and Quality Measures for Cardiac Rehabilitation. J Am Coll Cardiol 2018;2018:1814-37.

22. Zwisler AD, Rossau HK, Nakano A, et al. The Danish Cardiac Rehabilitation Database. Clin Epidemiol 2016;8:451-6.

23. The Danish Clinical Registries. In English - The Danish Clinical Registries. http://www.rkkp.dk/in-english/ (accessed 1 Aug 2018).

24. Beaton DE, Bombardier C, Guillemin F, et al. Guidelines for the process of cross-cultural adaptation of self-report measures. Spine 2000;25:3186-91.

25. Ministeriet for Sundhed og Forebyggelse. Nationalt kvalitetsprogram for sundhedsområdet 2015-2018 [National quality program for the healthcare arena 2015-2018]. 2015 https://www.sum.dk/Aktuelt/ Publikationer.aspx.

26. Damschroder LJ, Aron DC, Keith RE, et al. Fostering implementation of health services research findings into practice: a consolidated framework for advancing implementation science. Implement Sci 2009;4:50.

27. Granström E, Hansson J, Sparring V, et al. Enhancing policy implementation to improve healthcare practices: The role and strategies of hybrid national-local support structures. Int J Health Plann Manage 2018;33:e1262-e1278.

28. Bunce AE, Gold R, Davis JV, et al. "Salt in the Wound": Safety Net Clinician Perspectives on Performance Feedback Derived From EHR Data. J Ambul Care Manage 2017;40:26-35.

29. Berwick DM, James B, Coye MJ. Connections between quality measurement and improvement. Med Care 2003;41:I-30.

30. Nilsen P, Bernhardsson S. Towards evidence-based physiotherapy research challenges and needs. J Physiother 2013;59:143-4.

31. Egholm CL, Helmark C, Doherty P, et al. "Struggling with practices" - a qualitative study of factors influencing the implementation of clinical quality registries for cardiac rehabilitation in England and Denmark. BMC Health Serv Res 2019;19:102.

32. Gude WT, van Engen-Verheul MM, van der Veer SN, et al. How does audit and feedback influence intentions of health professionals to improve practice? A laboratory experiment and field study in cardiac rehabilitation. BMJ Qual Saf 2017;26:279-87.

33. Parand A, Dopson S, Renz A, et al. The role of hospital managers in quality and patient safety: a systematic review. BMJ Open 2014;4:e005055

34. Wilkinson JE, Nutley SM, Davies HT. An exploration of the roles of nurse managers in evidence-based practice implementation. Worldviews Evid Based Nurs 2011;8:236-46. 